\title{
Do joint geometrical properties influence the fracturing behaviour of jointed rock? An investigation through joint orientation
}

\author{
P. L. P. Wasantha P. G. Ranjith • \\ Q. B. Zhang $\cdot$ T. Xu
}

Received: 4 February 2015/Accepted: 17 April 2015/Published online: 2 June 2015

(C) Springer International Publishing Switzerland 2015

\begin{abstract}
Failure of brittle rock is often progressive and understanding the fracture development process within rock masses is important to identify the precursors of failures. Joints in rock masses influence the fracture progression behavior and we studied the influence of joint orientation on fracture progression in jointed rock. Undrained triaxial tests were conducted on $54 \mathrm{~mm}$ diameter and $108 \mathrm{~mm}$ high intact and singly-jointed sandstone specimens. The joints in jointed specimens were made rough (joint roughness coefficient $=10-12$ ) and embedded in six different orientations $-0^{\circ}, 30^{\circ}, 45^{\circ}$, $60^{\circ}, 75^{\circ}$ and $90^{\circ}$ —and three different combinations of confining and initial pore-water pressures were considered (confining pressure/pore-water pressure $=4 / 1$,
\end{abstract}

P. L. P. Wasantha $(\varangle) \cdot$ P. G. Ranjith

Deep Earth Energy Laboratory, Department of Civil

Engineering, Building 60, Monash University, Melbourne,

VIC 3800, Australia

e-mail: wasantha.liyanage@monash.edu

P. G. Ranjith

e-mail: ranjith.pg@monash.edu

Q. B. Zhang

Mining Engineering Division, Department of Civil

Engineering, Building 60, Monash University, Melbourne,

VIC 3800, Australia

e-mail: qianbing.zhang@monash.edu

T. Xu

Center for Rock Instability and Seismicity Research, Northeastern University, Shenyang 110006, China

e-mail: xutao@mail.neu.edu.cn
10/4 and 25/10 MPa). An acoustic emission (AE) monitoring system was employed during all tests to monitor the fracture development within the test specimens. The post-failure patterns of specimens displayed three different failure mechanisms - shearing through intact material, sliding along the joint and a mixture of both shearing and sliding-depending on the joint orientation and confining pressure. The fracture progression behavior of the specimens showed a strong correlation with these failure mechanisms. Intact specimens and specimens with joints oriented at $0^{\circ}, 30^{\circ}, 90^{\circ}$ failed by shearing. Nevertheless, the AE patterns of intact specimens and specimens with $90^{\circ}$-oriented joints contrasted with those of specimens with joints oriented at $0^{\circ}$ and $30^{\circ}$. Specimens with joints oriented at $60^{\circ}$ failed by sliding with a constant rate of acoustic event generation starting from the beginning of deviatoric loading. A mixed failure mechanism was observed for specimens with joints oriented at $45^{\circ}$ and $75^{\circ}$. While the characteristics of both sliding and shearing failure were observed from the $\mathrm{AE}$ patterns of both $45^{\circ}$ and $75^{\circ}$ orientations, the shearing failure component of the $75^{\circ}$ case was found to be a result of experimental limitations rather than real behavior. Finally, we propose a family of typical AE curves to assist with the characterization of the fracture progression behavior of jointed rock by taking confining pressures and failure mechanisms into consideration.

Keywords Joint orientation · Fracture development $\cdot$ Acoustic emission 


\section{Introduction}

The heterogeneous nature of rock masses caused by the discontinuities present within them complicates the mechanical response of rock. Discontinuities, commonly known as joints, can have any geometry (orientation, length, surface roughness etc.) within a rock mass and these geometrical properties significantly influence the mechanical behavior of rock. A number of research studies have been reported in the literature which incorporate joint geometrical properties in describing rock mechanical behavior (e.g. Singh et al. 2002; Ramamurthy and Arora 1994; Yang et al. 1998; Wasantha et al. 2011, 2012a, 2014b). To thoroughly understand the mechanical behavior of rock masses, it is also important to understand the fracture development process leading to failure upon loading. Failure of brittle rock is progressive, although it appears to be sudden in many cases, and a number of studies have been devoted to the characterization of the fracture propagation behavior of different rock types (e.g. Eberhardt et al. 1999; Scholz 1968; Martin and Chandler 1994; Peng and Johnson 1972). Although efforts have been made to correlate the strength and deformational properties with joint geometrical parameters, since the fracture progression behavior of jointed rock has been scarcely studied, the effects of joint geometrical properties on the fracture progression behavior of jointed rock are not well understood. Therefore, this paper is intended to contribute to filling this research gap by investigating the influence of joint orientation on the fracture progression behavior of singly-jointed sandstone under undrained triaxial conditions. A comprehensive review of the literature related to the effect of joint orientation on rock mechanical behavior, fracture progression in rock and the use of acoustic emission (AE) monitoring to study rock fracturing is presented below.

\subsection{Effect of joint orientation on rock mechanical behavior}

Results of previous studies show a significant influence of joint orientation on rock mechanical response under both confined and unconfined stress conditions (e.g. Yang et al. 1998; Kulathilake et al. 2001; Singh et al. 2002; Ranjith et al. 2004; Kumar and Das 2005; Tiwari and Rao 2004; Ramamurthy and Arora 1994;
Wasantha et al. 2011). In general, the variation of strength versus joint orientation revealed by the vast majority of these studies is consistent with the 'sliding plane of weakness' model proposed by Jaeger et al. (2007) (Eq. 1).

$\sigma_{1}=\sigma_{3}+\frac{2\left(S_{w}+\mu_{w} \sigma_{3}\right)}{\left(1-\mu_{w} \cot \beta\right) \sin 2 \beta}$

where $\sigma_{1}$ is the major principal stress, $\sigma_{3}$ is the minor principal stress, $S_{w}$ is the joint cohesion, $\mu_{w}$ is the joint friction coefficient $\left(\mu_{w}=\tan \phi_{w}\right.$, where $\phi_{w}$ is the joint friction angle) and $\beta$ is the joint orientation measured from the minor principal stress direction.According to the above sliding plane of weakness model, the critical joint orientation (i.e. the orientation that corresponds to minimum strength $)$ is $\left(45^{\circ}+\frac{\phi_{w}}{2}\right)$. Triaxial experiments by Tiwari and Rao (2004) and Ramamurthy and Arora (1994) showed that increasing confining pressure decreases the influence of joint orientation on rock mechanical response, as the higher normal stress acting on the joint at higher confining pressures imposes a greater resistance against sliding along the joint.

The main focus of most previous studies has been to investigate the effect of joint orientation on the strength and deformational properties of jointed rock. However, there have been some other studies that investigate the effect of joint orientation on other characteristics of rock behaviour. For example, Wasantha et al. (2014a) investigated the energy releasing behaviour during deformation of bedded sandstone with beddings in different orientations using $\mathrm{AE}$ monitoring, Wasantha et al. (2014b) studied the effect of joint orientation on pore-water pressure response during undrained deformation of singly-jointed sandstone, and Gong et al. (2005) studied the effect of joint orientation on rock fragmentation by tunnel-boring machine (TBM) cutters.

\subsection{Fracture progression in brittle rock}

Fracturing of brittle rock is a process through which existing bonds are broken and new surfaces are created (Eberhardt et al. 1999). Because failure begins by breaking the inter-granular bonds, the microstructure of a rock has a significant influence on the fracture progression behavior. Brittle fracturing of different rock types has been studied by many researchers (Brace et al. 1966; Scholz 1968; Peng and Johnson 
1972; Tapponnier and Brace 1976; Wong and Chau 1997; Eberhardt et al.1999; Wong et al. 2001; Alkan et al. 2007; Wong and Wu 2014). While the majority of these studies tested intact rock, Ranjith et al. (2004) used singly- and multiply-fractured granitic rock and characterized the behavior under uniaxial compression. Their results showed that crack initiation and damage occur at lower levels of stress when multiple fractures are present.

The fracture development process in brittle rock has been divided into three phases in the literature: crack closure, stable crack propagation, and unstable crack propagation. During the initial phase of loading, preexisting micro-cracks are closed (this is known as the crack closure phase) and the duration that the crack closure lasts depends on the initial crack density and crack geometry within the rock sample (this phase can even be absent for some rocks). A brittle rock specimen behaves in a linear elastic manner after the pre-existing cracks are closed, until it reaches a stress level at which new cracks are formed (this is known as crack initiation). Stable crack propagation begins immediately after the crack initiation followed by unstable crack propagation, which continues until failure. The instant at which the stable crack propagation transforms to unstable crack propagation is known as crack damage.

\subsection{AE monitoring for characterizing rock fracturing}

Several methods, including stress-strain relationships, scanning electron microscopy, photo-elasticity and $\mathrm{AE}$ monitoring, have been used to identify the different phases of the rock fracturing process (Ranjith et al. 2008). Of these, the AE monitoring technique has been of particular interest to researchers, as it is a simple method with proven reliability (Perera et al. 2011; Rathnaweera et al. 2013; Perera and Ranjith 2013).

AEs are produced by rapid micro-crack growth and usually provide vital information related to the failure of rock (Lockner 1993). AE has been used for numerous rock mechanics applications since the late 1930s. Koerner et al. (1981) reported eight different applications in rock mechanics which use AE monitoring techniques. These include rock mines, tunnels, slopes, hydraulic fracturing and earthquake precursor monitoring. Obert and Duvall (1942) is one of the earliest studies that used AE in rock mechanics, and they monitored $\mathrm{AE}$ release to predict rock bursts and mine failures. Lockner (1993) states that AE and seismology have significant overlaps, as both disciplines are concerned with the generation and propagation of elastic waves.

Externally-attached sensors are generally used in the $\mathrm{AE}$ technique to capture the elastic waves generated with the micro-crack development of a material undergoing stress changes. In general, 'AE counts' refer to the number of times the amplitude of an $\mathrm{AE}$ wave exceeds a specified threshold value. The characteristics of the cumulative $\mathrm{AE}$ counts versus stress curve have been used to identify the different phases of fracture propagation in brittle rocks. For example, Ranjith et al. (2004) reported that the curve is almost horizontal with very few or no AE counts during the crack closure phase, followed by stable fracture propagation where the curve shows a linear increase of cumulative AE counts with increasing stress. When the linear trend of the curve converts to an exponentially growing trend, it marks the beginning of the unstable crack propagation phase.

Although the fracture progression behaviour of intact rock has been well documented that of jointed rock coupled with joint geometrical properties has not been satisfactorily explored. Therefore, this paper provides an initial attempt to better understand the nature of fracture development in jointed rock by investigating the influence of joint orientation on the fracture progression behaviour of singly-jointed sandstone under undrained triaxial stress conditions. AE monitoring was used to characterize the fracture propagation process in the test specimens. The following section presents the details of the experimental method, followed by the results and discussion.

\section{Experimental work}

Hawkesbury sandstone, sourced from Sydney, Australia, was used for testing. According to Wasantha and Ranjith (2014), this sandstone is classified as quartz arenite and has a porosity of $13 \%$ (as determined by the water absorption method, which uses the difference of fully-saturated weight and oven-dried weight of a specimen to calculate the porosity), an average grain size of $293.6 \mu \mathrm{m}$, an average density of $2206 \mathrm{~kg} / \mathrm{m}^{3}$ and a dry uniaxial compressive strength of $39 \mathrm{MPa}$. A detailed description of the mechanical behavior of 
intact Hawkesbury sandstone under dry and undrained triaxial conditions is reported in Wasantha and Ranjith (2014). Ord et al. (1991) and Pells (2004) provide further information on the physico-mechanical properties of Hawkesbury sandstone.

\subsection{Sample preparation, testing apparatus and testing procedure}

Core specimens $54 \mathrm{~mm}$ in diameter and $108 \mathrm{~mm}$ high were prepared using a small-scale sandstone block and the end surfaces of specimens were ground to make them smooth and parallel to the long axis. An artificial rough inclined joint was then embedded in each specimen using water-jet cutting. Water-jet cutting is a high-precision technique of replicating natural joint surfaces (Haberfield and Seidel 1999), in which a high-pressure water jet follows a pre-defined profile, creating a split across the material. We selected a joint surface profile analogous to the surface profile with a joint roughness coefficient (JRC) of 10-12, as defined in the JRC scale of Barton (1973) and used it for the joints in all specimens. Six different joint orientations were considered: $0^{\circ}, 30^{\circ}, 45^{\circ}, 60^{\circ}, 75^{\circ}$ and $90^{\circ}$. A typical specimen set with one specimen from each joint orientation is shown in Fig. 1. In addition to the jointed specimens, a set of intact specimens was also tested under each test condition considered.

A newly-developed high-pressure triaxial apparatus, housed at the Civil Engineering Laboratory, Monash University, was used for the testing of all specimens. The features of the apparatus and the general testing procedure are described in Wasantha et al. (2013a). Prepared samples were pre-saturated in a water bath under vacuum pressure before being placed in the apparatus for testing, to minimize the time taken for the samples to become saturated in the apparatus. The samples were enclosed in flexible membranes and firmly attached to the apparatus. First the confining pressure was applied to a pre-determined value. Pore-water pressure was then applied from the bottom of the specimen and the pore-water outlet was left open until some amount of water was observed to drip to ensure that no air was trapped in the system. As all the tests were performed under undrained triaxial conditions, the outlet was then closed and sufficient time was allowed to stabilize the pressures. Finally, the deviatoric stress was applied until the failure of the samples. A complete description of the testing procedure can be found in Wasantha et al. (2014b).

Confining pressures of 4,10 and $25 \mathrm{MPa}$ were selected with initial pore-water pressures of 1,4 , $10 \mathrm{MPa}$, respectively. The corresponding pore-water pressure for each confining pressure was determined considering the depth that each confining pressure represents, assuming a density of $2500 \mathrm{~kg} / \mathrm{m}^{-3}$ for sandstone (Wasantha et al. 2014b). The data acquisition system recorded the load-displacement variations, volume changes and pore-water pressure changes. The AE monitoring system recorded the data related to fracture propagation behavior during all tests, and the next section describes this procedure in detail.

\subsection{AE monitoring system}

A commercially available Physical Acoustics Corporation (PAC) PCI-2 AE system was used for the study and employed during all tests, with the settings

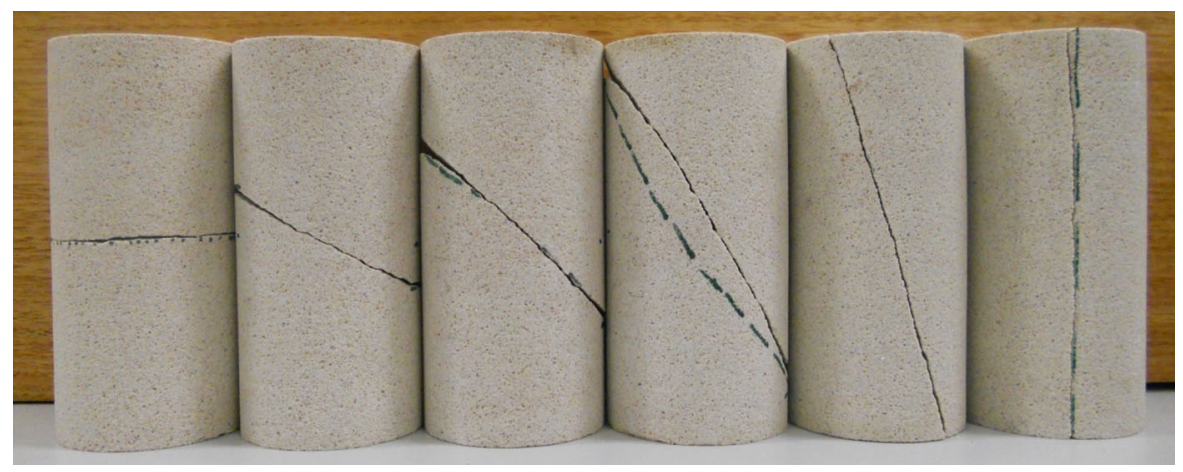

Fig. 1 Representative jointed sandstone samples for all joint orientations considered (from left to right $0^{\circ}, 30^{\circ}, 45^{\circ}, 60^{\circ}, 75^{\circ}$ and $90^{\circ}$ ) (after Wasantha et al. 2014b) 
Table 1 Settings used on the PAC PCI-2 AE system (Wasantha et al. 2013a)

\begin{tabular}{ll}
\hline Parameter & Setting \\
\hline Sensor type & PAC R6a \\
Sensor resonant frequency $(\mathrm{kHz})$ & $55(90)$ \\
Sensor frequency range $(\mathrm{kHz})$ & $35-100$ \\
Sensor directionality $(\mathrm{dB})$ & \pm 1.5 \\
Pre-amplification or gain $(\mathrm{dB})$ & 20,40 or 60 \\
Post-amplification $(\mathrm{dB})$ & 0 \\
Trigger threshold $(\mathrm{dB})$ & 55 \\
Sampling rate & 1 MSPS \\
Pre-trigger $(\mu \mathrm{s})$ & 256 \\
Peak definition time $(\mu \mathrm{s})$ & 50 \\
Hit definition time $(\mu \mathrm{s})$ & 200 \\
Hit lockout time $(\mu \mathrm{s})$ & 300 \\
Max duration $(\mathrm{ms})$ & 100 \\
No. hits per event & Minimum: 5, maximum 8 \\
Sensor mounting method & 2211 silicone \\
& compound-geophysical \\
& grade/high vacuum \\
grease
\end{tabular}

adjusted as shown in Table 1. Two transducers were used to capture the AEs and they were attached to the pressure vessel of the apparatus at a height approximately coinciding with the mid-height of the specimen under test. Figure 2 displays the testing arrangement, showing the transducers attached to the pressure vessel. It should be noted that the transducers were not in direct contact with the test specimens, as such an experimental arrangement of high-pressure triaxial testing with the transducers in direct contact with the specimen is extremely complex. As Lockner (1993) states, placing the transducers directly on the specimen is necessary to obtain a picture of the crack propagation path and its location within the specimen. However, since the aim of this study was to investigate the fracture propagation process of test specimens in relation to increasing deviatoric stress, placement of the transducers external to the specimen was sufficient (previous trial experiments showed that the AEs are effectively transmitted through the confining fluid and pressure vessel wall such that the transducers can capture these at the surface of the vessel).

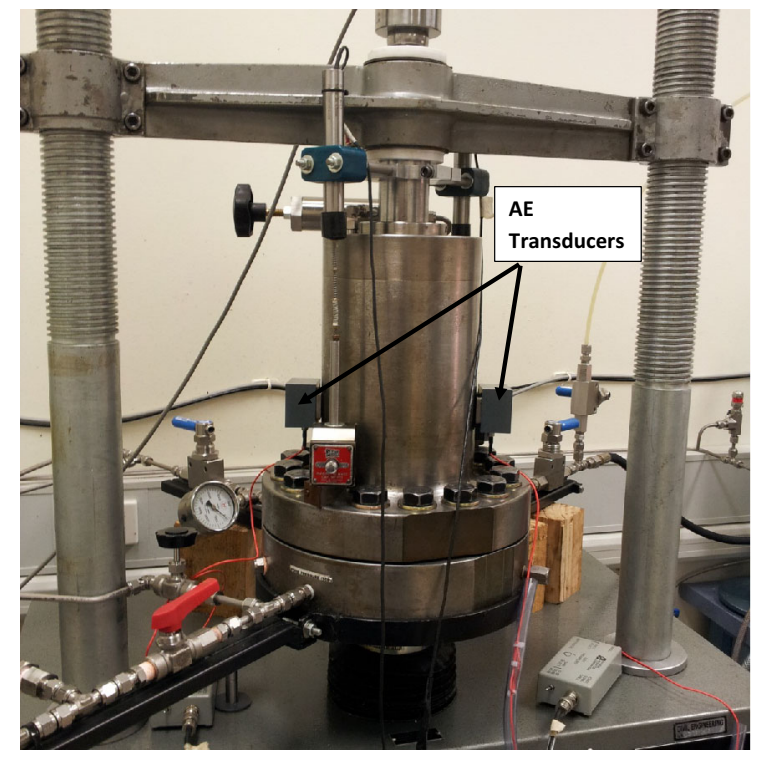

Fig. 2 Arrangement of the testing apparatus with $\mathrm{AE}$ transducers

The deviatoric loading and acoustic count recording were begun simultaneously such that the deviatoric stress and acoustic count generation could be correlated based on the time.

\section{Results and discussion}

Deviatoric stress was plotted against time for all the specimens, and one typical curve for each condition is displayed in Fig. 3. We then plotted cumulative AE counts ratios (i.e. the ratio of $\mathrm{AE}$ count to total number of AE counts) versus time for all the specimens, and one representative curve for each test condition is shown in Fig. 4.

Having analyzed the characteristics of post-failure patterns, Wasantha et al. (2014b) reported three failure mechanisms: (1) shearing, which is failure through the intact material, (2) sliding, which is failure along the joint and (3) mixed, which is a combination of both the shearing and sliding mechanisms. Considering the variation of failure mechanisms with different joint orientations and confining pressures, these researchers proposed a graphical plot to determine the failure mechanisms under different joint orientations and confining pressures (Fig. 5).

From the AE curves of Fig. 4 a strong correlation between fracture progression behaviour and failure 

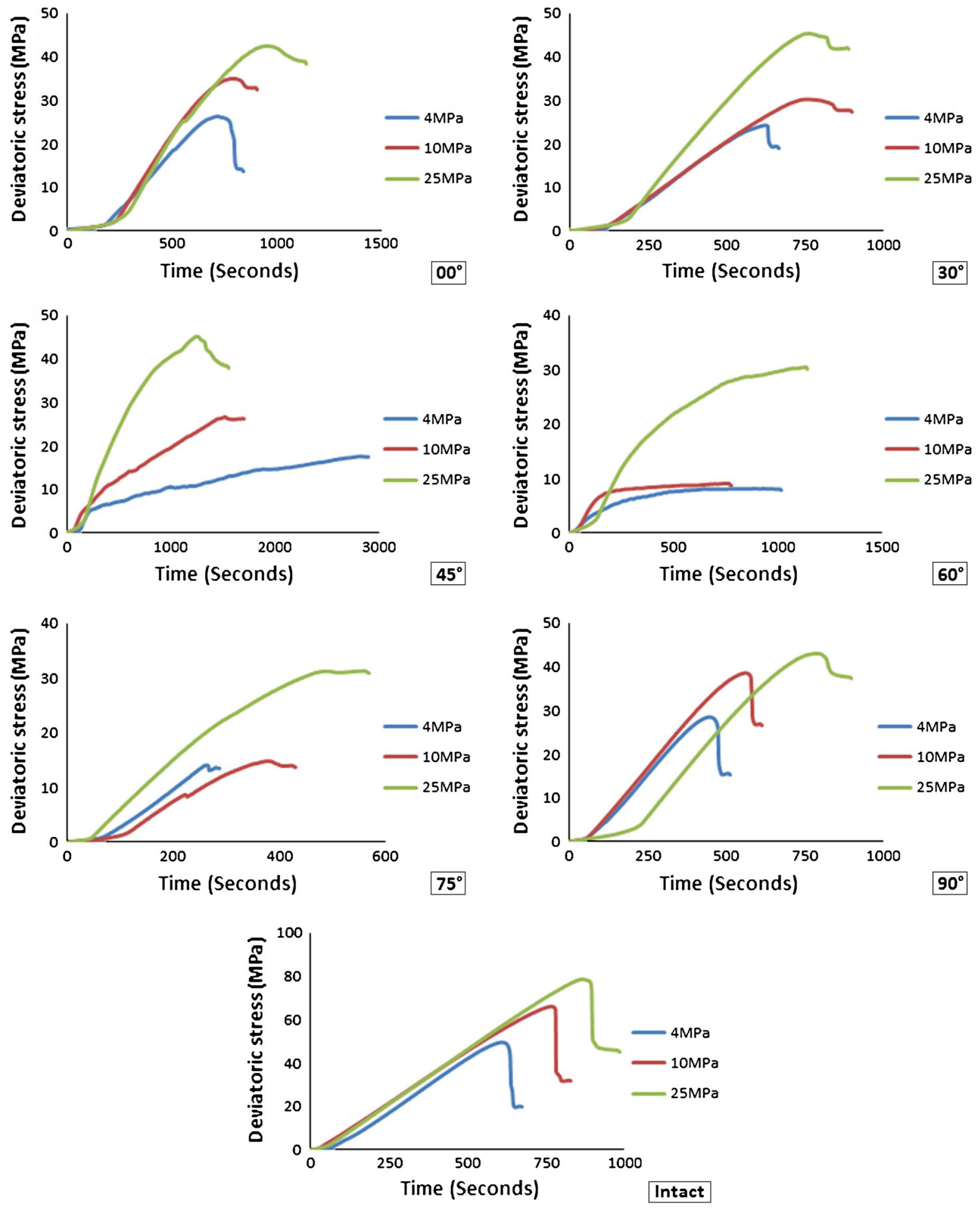

Fig. 3 Typical deviatoric stress versus time curves of the singly-jointed and intact specimens 

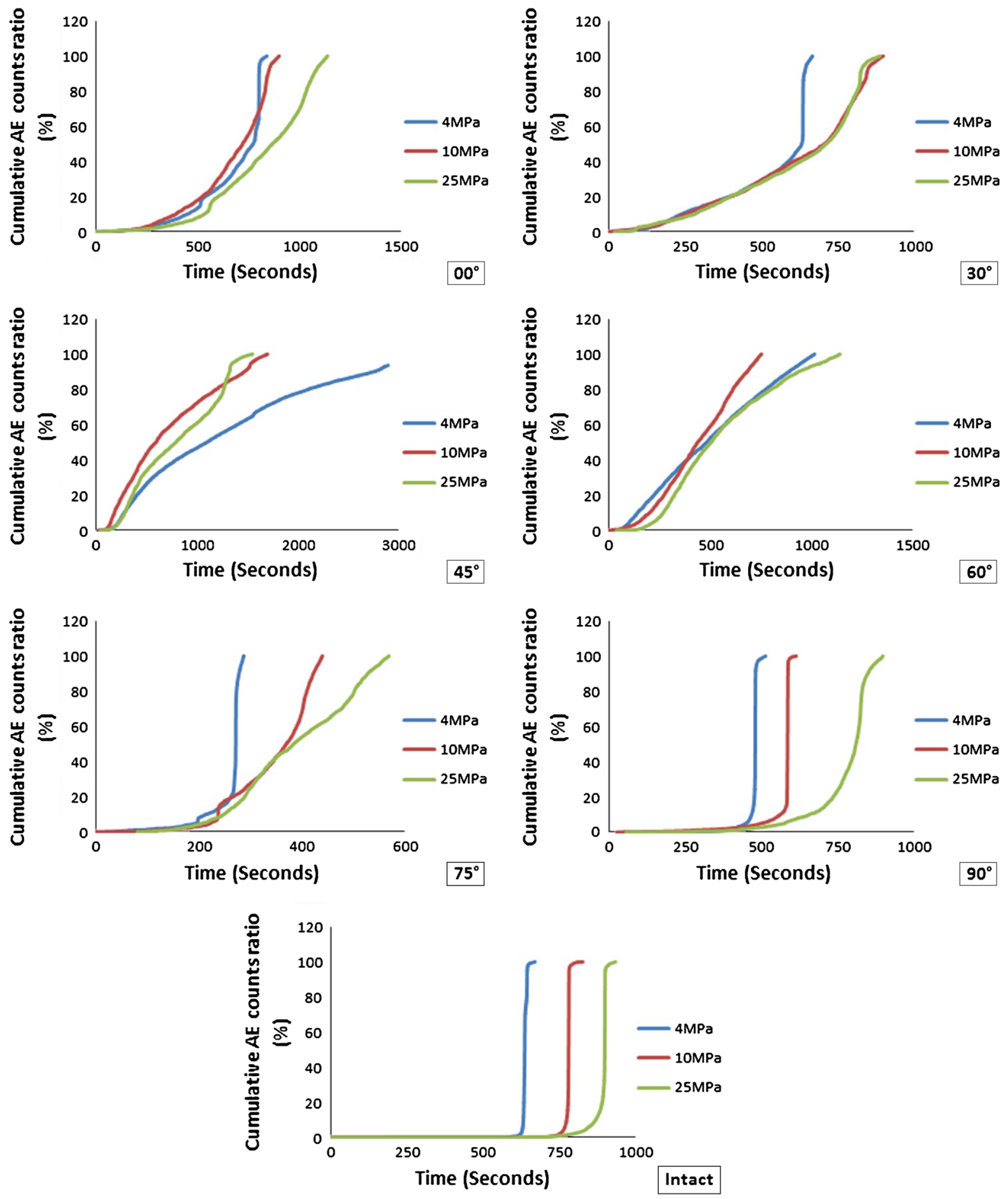

Fig. 4 Typical cumulative AE counts ratio versus time curves of the singly-jointed and intact specimens

mechanisms can be observed. For intact specimens, in which failure occurs by shearing through the material, most $\mathrm{AE}$ events occur at or very close to failure
(Fig. 4). At low confining pressures, a large proportion of acoustic energy is released at or very close to failure, which shows brittle failure characteristics. 


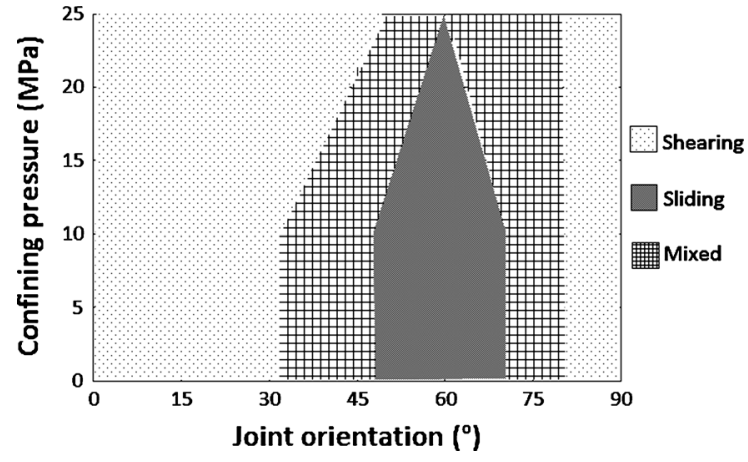

Fig. 5 Failure mechanisms observed from testing for the various confining pressures and joint orientations considered (after Wasantha et al. 2014b)

However, with increasing confining pressure, acoustic energy release begins progressively earlier with respect to failure as a result of the earlier beginning of micro-crack development, and this indicates the sandstone specimens become more quasi-brittle with increasing confining pressure (Wasantha and Ranjith 2014; Wasantha et al. 2012b).

According to the failure mode plot of Fig. 5, the specimens with horizontally- and vertically-oriented joints (i.e. $0^{\circ}$ and $90^{\circ}$ ), and specimens with joints oriented at $30^{\circ}$ fail by shearing through the intact material with minor or no influence of the joint on the failure mode. As a result, similar trends of AE versus time curves, as observed for intact specimens, can be expected. Although vertically-jointed specimens show patterns of $\mathrm{AE}$ curves similar to those of intact specimens, horizontally-jointed specimens and those with joints oriented at $30^{\circ}$ show that the $\mathrm{AE}$ begins at very early stages of deviatoric loading. We hypothesize that this earlier occurrence of acoustic events is an indication of damage to the asperities of rough joints after a quick initial settlement of the joint (relatively higher normal stress acting on horizontal and $30^{\circ}$ oriented joints can encourage the joint settlement and asperity damage processes). With increasing deviatoric loading, further asperity damage and micro-crack generation within the intact material occur, but it is difficult to distinguish which mechanism is which from the curves (under low confining pressures, i.e. $4 \mathrm{MPa}$, both $0^{\circ}$ and $30^{\circ}$ orientations show a sudden release of some acoustic energy at the failure, which could be due to the more brittle characteristics this sandstone exhibits at lower confining pressures).
At $60^{\circ}$ joint orientation, AEs begin with the beginning of deviatoric loading and that trend continues throughout the loading period. This pattern of acoustic event generation is consistent with the sliding failure mechanism observed at $60^{\circ}$ joint orientation (Fig. 5), where the acoustic events are constantly generated, with the asperity degradation occurring with continuous sliding. The AE curves of Fig. 4 for $60^{\circ}$ joint orientation, which are nearly linear at early stages of deviatoric loading, show a slight gentling of the slopes at later stages of deviatoric loading. This is possibly a product of the resistance imposed by the membrane to excessive shearing, which eventually depresses the sliding. By analysing the AE curves of the jointed specimens that fail by shearing and sliding (except for $90^{\circ}$ ), it can be seen that the curves of both failure mechanisms show common characteristics, where the AEs begin at the same time or just after the beginning of deviatoric loading. However, when the failure mechanism is shearing, the AE curves form with increasing gradient as a result of the generation of AEs by micro-cracking within the intact material, in addition to the AEs produced from the asperity damage. In contrast, the AE curves for sliding failure form a linear trend. This difference of the patterns of $\mathrm{AE}$ curves for shearing and sliding failures can be used to distinguish the two failure mechanisms.

Mixed failure mode was observed for both $45^{\circ}$ and $75^{\circ}$ joint orientations (Fig. 5). At $4 \mathrm{MPa}$ confining pressure, the trend of the $\mathrm{AE}$ curve of the $45^{\circ}$ joint orientation is closely analogous to that of specimens which failed by sliding, which suggests that at lower confining pressures failure tends to take place predominantly by sliding. Nevertheless, under higher confining pressures, AE curves show a sudden occurrence of some acoustic events at failure, which indicates some intact material failure in addition to sliding (i.e. mixed failure). These observations can be understood considering the fact that greater confining pressures offer greater resistance to sliding, which finally encourages material failure. In the case of the $75^{\circ}$ joint orientation, it can be clearly seen that until a certain level of deviatoric loading no or very minor AEs occur, followed by a sudden generation of acoustic events, indicating intact material failure (this sudden acoustic event occurrence is more pronounced at 4 and $10 \mathrm{MPa}$ confining pressures). After this intact material failure, the AE curves display a trend that closely resembles the trend of sliding failure. Based on 
this direct observation, the failure mode can be technically categorized as a mixed mode failure, since the failure is a combination of sliding along the joint and shearing through the intact material. However, it should be noted that this initial material failure is an experimental artefact rather than a real occurrence. The termini of joints oriented at $75^{\circ}$ orientation intersect the two parallel surfaces of test specimens due to the limited slenderness (height-to-diameter ratio) of the test specimens, and this creates an unrealistic resistance to free sliding, as shown in Fig. 6 (Wasantha et al. 2013b). Therefore, before the actual sliding failure begins, some intact material failure in the vicinity of joint termini takes place, as observed from the $\mathrm{AE}$ curves as well as from the post-failure images shown in Wasantha et al. (2014b). Hence, we suggest that considering the $75^{\circ}$ as a joint orientation that yields sliding failure is more meaningful for the purpose of studying fracture progression behavior.

The above results clearly exhibit a strong correlation between the fracture progression behavior of singly-jointed sandstone and the failure mechanisms. Therefore, the pre-requisite to characterize the fracture progression in jointed rock with joints in different orientations is to understand the failure mechanisms corresponding to different joint orientations and confining pressures. Using the results of this paper, the patterns of $\mathrm{AE}$ event accumulation can be predicted when the joint orientation (and failure mechanism) is known, and the failure mechanism can be predicted when the AE generation pattern is known (Fig. 6). Furthermore, when all three information sets-joint orientation, failure mechanism and $\mathrm{AE}$ event generation pattern-are available, their accuracy and reliability can be cross-checked. To assist with this process, we propose a family of typical $\mathrm{AE}$ curves, as shown in Fig. 7, to represent the expected characteristics of the $\mathrm{AE}$ curves for different failure mechanisms and confining pressures.

In the case of shearing failure, intact and verticallyjointed specimens showed AE curves that are different to those of the other jointed specimens failed by shearing. Therefore, two different types of typical AE curves are presented in Fig. 7 for shearing failure. The AE curves of Fig. 7 can be used as a guide to understand the fracture progression behaviour of jointed rocks. However, it should be noted that the maximum confining pressure considered was $25 \mathrm{MPa}$ and the tested Hawkesbury sandstone showed a more quasi-brittle behaviour at $25 \mathrm{MPa}$ confining pressure. Moreover, this testing program considered only unfilled rough joints, and tests were conducted under undrained triaxial stress conditions where pore-water pressure fluctuations were allowed.

\section{Conclusions}

A series of undrained triaxial experiments was performed on intact and singly-jointed sandstone specimens to investigate the influence of joint orientation on the fracture progression behavior of jointed rock. Joints in jointed specimens were made rough with a JRC of 10-12 and embedded in six different orientations $-0^{\circ}$, $30^{\circ}, 45^{\circ}, 60^{\circ}, 75^{\circ}$ and $90^{\circ}$. Tests were conducted under three different combinations of confining and initial pore-water pressures; i.e. confining pressure/initial pore-water pressure $=4 / 1,10 / 4$ and 25/10 MPa. Facture progression in specimens was monitored during all tests using an AE monitoring system.

Analysis of post-failure patterns of specimens revealed three distinct failure mechanisms: (1)
Fig. 6 Arrangement of a joint in a rock sample with height-to-diameter ratio of 2. a When the joint angle is $<63^{\circ}$, b when the joint angle is $=63^{\circ}$, and $\mathbf{c}$ when the joint angle is $>63^{\circ}$ (after Wasantha et al. 2013b)

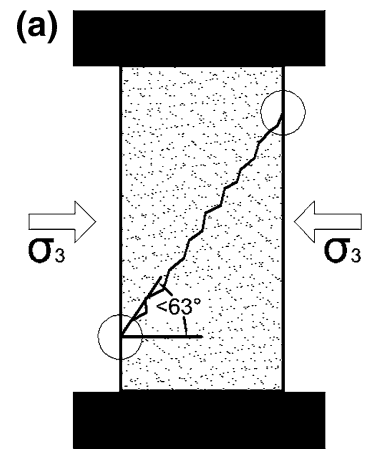

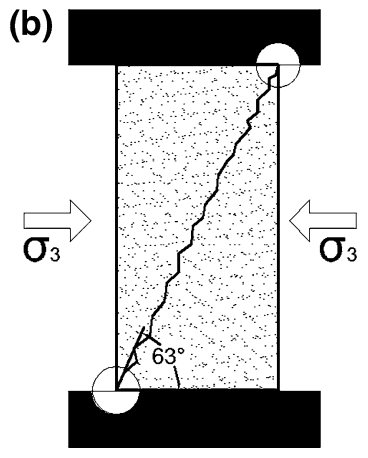

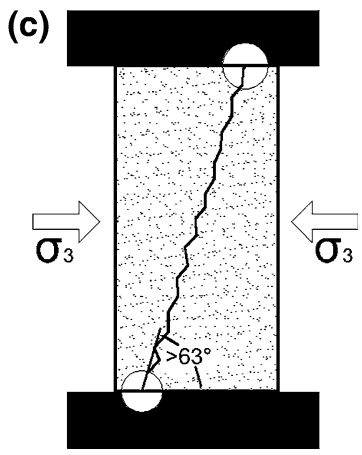


Shearing- intact \& vertically jointed

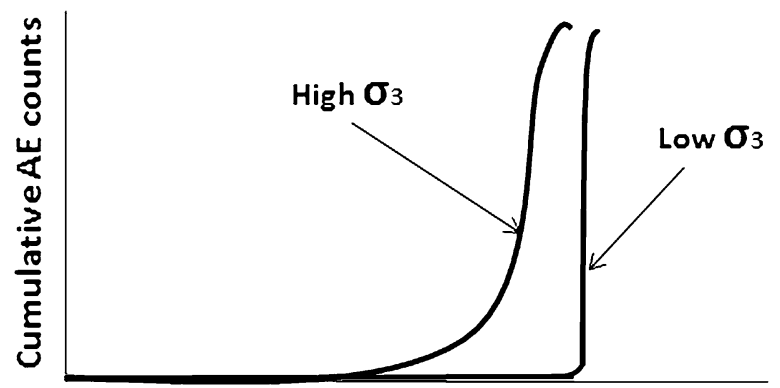

Time

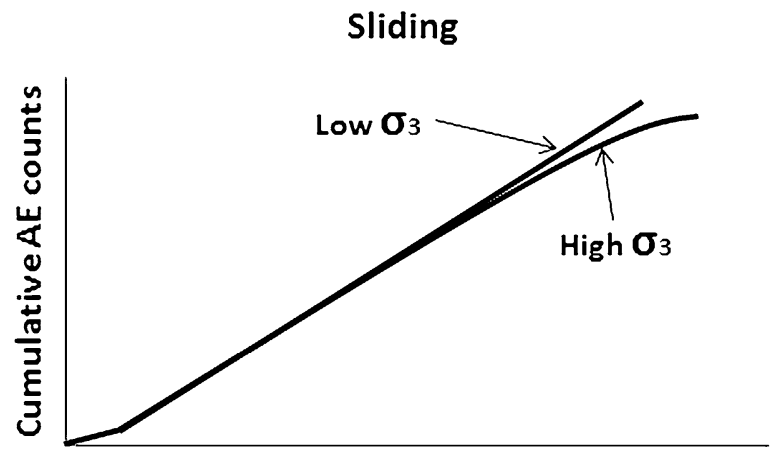

Time
Shearing- other jointed

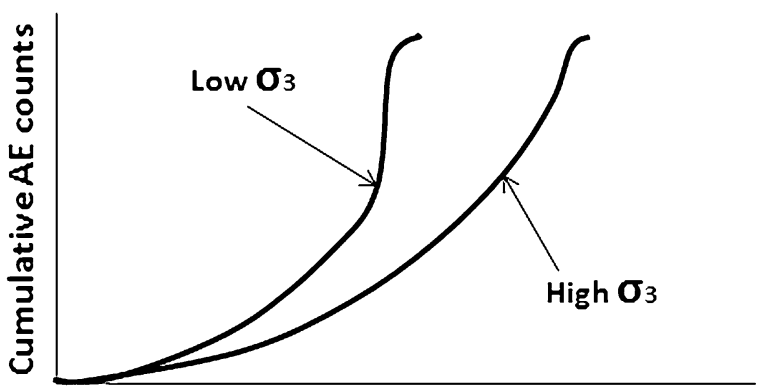

Time

Mixed

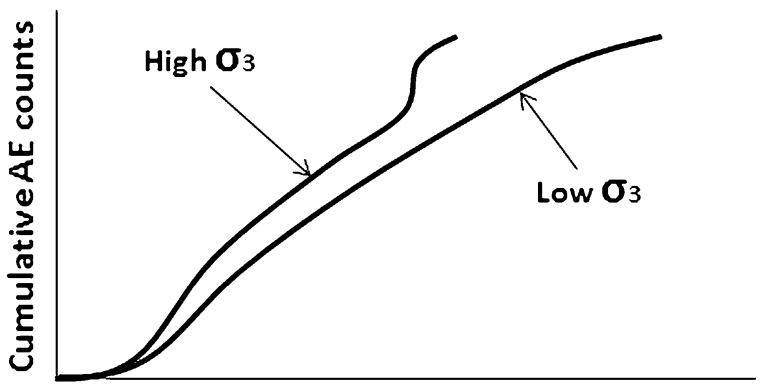

Time

Fig. 7 Typical curves of cumulative AE counts versus time for different failure mechanisms and confining pressures

shearing, which is a failure through the intact material, (2) sliding, which is a failure along joints and (3) mixed, which is a combination of shearing and sliding. The failure mechanisms of specimens were observed to be dependent on joint orientation as well as the confining pressure. According to the results of $\mathrm{AE}$ analysis, a strong correlation between the fracture progression behavior and the corresponding failure mechanism was observed. In the case of shearing failure, which was observed for intact specimens and jointed specimens with joints oriented at $0^{\circ}, 30^{\circ}$ and $90^{\circ}$ angles, two types of AE patterns were observed. For the $0^{\circ}$ and $30^{\circ}$ orientations, AE generation started just after the deviatoric loading started, while such an early occurrence of acoustic events was not observed for intact and $90^{\circ}$ orientation cases. We hypothesize that this is a product of damage to the asperities of joints due to the higher normal stress acting on them. In case of the $60^{\circ}$ joint orientation, for which the specimens failed by sliding, AEs were observed to accumulate at a constant rate starting from the application of deviatoric loading. Specimens with joints oriented at $45^{\circ}$ and $75^{\circ}$ showed a mixed failure mechanism. Nonetheless, the AE patterns displayed inconsistent characteristics for these two joint orientations. Characteristics of $\mathrm{AE}$ generation related to both sliding along the joint and intact material shearing were observed for the $45^{\circ}$ joint orientation, which verifies the mixed failure mechanism. For the $75^{\circ}$ joint orientation, until a certain level of deviatoric loading no or very few acoustic events were generated, and after a sudden occurrence of large acoustic events, which corresponds to intact material failure, AEs were generated constantly. This observation indicates that the initial material failure is followed by sliding failure, which technically suggests a mixed failure mechanism. However, it was found that the initial material failure is a product of the limited slenderness of the test specimens, since the termini of joints intersect the top and bottom surfaces of specimens for the joint arrangement of the $75^{\circ}$ orientation, causing a material failure in the vicinity of intersections to accommodate the free sliding failure. Hence, it is suggested that sliding failure is more appropriate than 
mixed failure in describing the fracture progression behavior of specimens with joints with $75^{\circ}$ joint orientation. Finally, a family of typical AE pattern curves was introduced as an approach to correlate the fracture progression behavior of jointed rock with $\mathrm{AE}$ monitoring.

\section{References}

Alkan H, Cinar Y, Pusch G (2007) Rock salt dilatancy boundary from combined acoustic emission and triaxial compression tests. Int J Rock Mech Min Sci 44:108-119

Barton N (1973) Review of a new shear strength criterion for rock joints. Eng Geol 7:287-332

Brace WF, Paulding B, Scholz C (1966) Dilatancy in the fracture of crystalline rocks. J Geophys Res 71:3939-3953

Eberhardt E, Stimpson B, Stead D (1999) Effects of grain size on the initiation and propagation thresholds of stress-induced brittle fractures. Rock Mech Rock Eng 32(2):81-99

Gong QM, Zhao J, Jiao YY (2005) Numerical modeling of the effects of joint orientation on rock fragmentation by TBM cutters. Tunn Undergr Sp Technol 20(2):183-191

Haberfield CM, Seidel JP (1999) Some recent advances in the modeling of soft rock joints in direct shear. Geotech Geol Eng 17:177-195

Jaeger JC, Cook NGW, Zimmerman RW (2007) Fundamentals of Rock mechanics, 4th edn. Blackwell, Oxford

Koerner RM, McCabe WM, Lord AE (1981) Overview of acoustic emission monitoring of rock structures. Rock Mech 14:27-35

Kulathilake PHSW, Malama B, Wang J (2001) Strength predictions for jointed rocks in confined and unconfined states. Int J Rock Mech Min Sci 38:641-657

Kumar D, Das SK (2005) An experimental study of the parameters influencing ultimate bearing strength of weak floor strata using physical modelling. Geotech Geol Eng 23:1-15

Lockner D (1993) The role of acoustic emission in the study of rock fracture. Int J Rock Mech Min Sci Geomech Abstr 30:883-899

Martin C, Chandler N (1994) The progressive fracture of Lac du Bonnet granite. Int J Rock Mech Min Sci Geomech Abstr 31(6):643-659

Obert L, Duvall W (1942) U.S. Bureau of Mines, rept. invest. RI-3654

Ord A, Vardoulakis I, Kajewski R (1991) Shear band formation in Gosford sandstone. Int J Rock Mech Min Sci 28:397-409

Pells PJN (2004) Substance and mass properties for the design of engineering structures in the Hawkesbury sandstone. Aust Geomech 39(3):1-21

Peng SS, Johnson AM (1972) Crack growth and faulting in cylindrical specimens of Chelmsford granite. Int J Rock Mech Min Sci Geomech Abstr 9:37-86

Perera MSA, Ranjith PG (2013) Effects of gaseous and supercritical carbon dioxide saturation on the mechanical properties of bituminous coal from the southern Sydney basin. Appl Energy 110:73-81
Perera MSA, Ranjith PG, Mironov P (2011) Effects of saturation medium and pressure on strength parameters of Latrobe Valley brown coal: carbon dioxide, water and nitrogen saturations. Energy 36(12):6941-6947

Ramamurthy T, Arora VK (1994) Strength predictions for jointed rocks in confined and unconfined states. Int J Rock Mech Min Sci Geomech Abstr 31:9-22

Ranjith PG, Fourar M, Pong SF, Chian W, Haque A (2004) Characterisation of fractured rocks under uniaxial loading states. Int J Rock Mech Min Sci 41:361-366

Ranjith PG, Jasinge D, Song JY, Choi SK (2008) A study of the effect of strain rate and moisture content on mechanical properties of concrete: use of acoustic emission. Int J Mech Mater 40(6):453-469

Rathnaweera TD, Ranjith PG, Perera MSA (2013) Salinity-dependent strength and stress-strain characteristics of reservoir rocks in deep saline aquifers: an experimental study. Fuel 122:1-11

Scholz CH (1968) Experimental study of the fracturing process in brittle rocks. J Geophys Res 73(1447):1453

Singh M, Rao KS, Ramamurthy T (2002) Strength and deformational behaviour of a jointed rock mass. Rock Mech Rock Eng 35:45-64

Tapponnier P, Brace WF (1976) Development of stress-induced microcracks in Westerly granite. Int J Rock Mech Min Sci Geomech Abstr 13:103-112

Tiwari RP, Rao KS (2004) Physical modelling of a rock mass under a true triaxial stress state. Int J Rock Mech Min Sci 41(3):Paper 2A 14

Wasantha PLP, Ranjith PG (2014) Water-weakening behavior of Hawkesbury sandstone in brittle regime. Eng Geol 178:91-101

Wasantha PLP, Ranjith PG, Haque A, Kodikara J, Bouazza A (2011) Implications of joint properties on the strength of a jointed rock mass. Adv Unsaturated Soil Geohazard Geoenviron Eng 258-266. doi:10.1061/47628(407)33

Wasantha PLP, Ranjith PG, Viete DR, Luo L (2012a) Influence of the geometry of partially-spanning joints on the uniaxial compressive strength of rock. Int J Rock Mech Min Sci 50:140-146

Wasantha PLP, Ranjith PG, Viete DR, Haque A, Bouazza A (2012b) Crack initiation stress for saturated sandstone in triaxial compression. In: Proceedings of the 46th US rock mechanics/geomechanics symposium, 24-27 June. ARMA, Chicago, p 228

Wasantha PLP, Darlington WJ, Ranjith PG (2013a) Characterization of mechanical behaviour of saturated sandstone using a newly developed triaxial apparatus. Exp Mech 53(5):871-882

Wasantha PLP, Ranjith PG, Viete DR (2013b) Specimen slenderness and the influence of joint orientation on the uniaxial compressive strength of singly jointed rock. J Mater Civil Eng 26(6):06014002

Wasantha PLP, Ranjith PG, Viete DR (2014a) Effect of joint orientation on the hydromechanical behavior of singly jointed sandstone experiencing undrained loading. J Geophys Res Solid Earth 119(3):1701-1717

Wasantha PLP, Ranjith PG, Shao SS (2014b) Energy monitoring and analysis during deformation of bedded-sandstone: use of acoustic emission. Ultrasonics 54(1):217-226 
Wong RHC, Chau KT (1997) The coalescence of frictional cracks and the shear zone formation in brittle solids under compressive stresses. Int J Rock Mech Min Sci 34(3-4): 335.e1-335.e12

Wong LNY, Wu Z (2014) Application of the numerical manifold method to model progressive failure in rock slopes. Eng Fract Mech 119:1-20
Wong RHC, Chau KT, Tang CA, Lin P (2001) Analysis of crack coalescence in rock-like materials containing three flawspart I: experimental approach. Int J Rock Mech Min Sci 38(7):909-924

Yang ZY, Chen JM, Huang TH (1998) Effect of joint sets on the strength and deformation of rock mass models. Int J Rock Mech Min Sci 35(1):75-84 